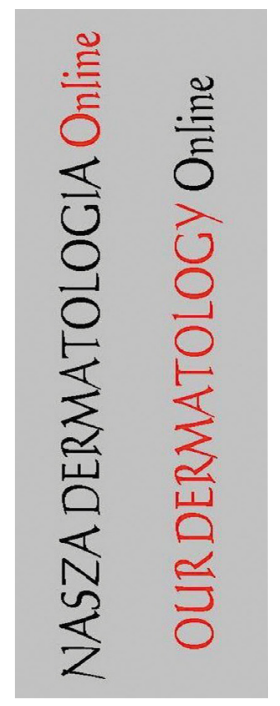

\title{
BLACK HAIRY TONGUE: A RARE SIDE EFFECT OF LINEZOLID
}

\author{
BLACK HAIRY TONGUE: RZADKIE DZIAŁANIE NIEPOŻĄDANE \\ LINEZOLIDU
}

Ilkay Bozkurt $^{1}$, Efsan Yontar $^{2}$, Mehmet Doganay ${ }^{1}$

${ }^{1}$ Department of Infectious Diseases and Clinical Microbiology, Erciyes University, Kayseri, Turkey

${ }^{2}$ Department of Dermatology, Erciyes University, Kayseri, Turkey

Corresponding author: Dr. Ilkay Bozkurt

drilkaybozkurt@gmail.com

Sir,

A rare side effect of linezolid in a patient was presented in this letter. A 40-year-old woman was admitted to the hospital 1 month ago because of the lesions on her face, around the right ear. On examination, she had multiple preauricular and post-auricular nodular lesions and the largest one was $1,5 \mathrm{~cm}$ in diameter. In the patients' previous medical history, she had a disease of systemic lupus erythematosus, diagnosed 20 years earlier that had been controlled with steroid for the previous 19 years. At the time of admission, she was receiving a combination of steroid and azathioprine for last 6 months. She was examined by magnetic resonance imaging (MRI) of the brain and multiple abscess formation was reported. Initially, trimethoprim-sulfamethoxazole $(15 \mathrm{mg} / \mathrm{kg}$ ) and ceftriaxone (1gr bid) was administered as empirical treatment. Initial antibiotic regimen was continued according to culture results from lesions. Nocardia species was isolated from the culture and found susceptible to ceftriaxone, trimethoprim-sulfamethoxazole and linezolid. At the second week of the antibiotic therapy, the lesions showed progression and pneumonic infiltration was developed. For this reason, trimethoprim-sulfamethoxazole regimen was switched to linezolid (600 mg bid). A black hairy discoloration on her tongue, especially right side appeared 10 days after initiating linezolid therapy (Fig. 1a). The patient denied any use of tobacco or alcohol. Despite this side affect, she well tolerated the therapy with linezolid. Nearly one week later, patients' tongue completely resolved with just brushing and applied a good oral hygiene (Fig. 1b). Black discoloration of tongue is a reaction pattern that can be related to some conditions such as medications, physiologic, metabolic and toxic disorders and exogenous substances like tobacco, alcohol, and crack cocaine [1].
It can be caused by drugs such as corticosteroids, lansoprazole, methyldopa and some antibiotics (cephalosporins, claritromycin, penicillins, sulfonamids and tetracyclines) $[2,3]$.

Linezolid is associated with some adverse events, mainly nausea, vomiting, diarrhea, and headaches. Thrombocytopenia and anemia also occur frequently in patients taking linezolid $[4,5]$. Black hairy tongue has been described before and the rate was reported as $0.2 \%$ in a large and controlled clinical study including 1498 patients received linezolid [5]. Although the exact pathogenesis is unclear, antibiotics such as linezolid associated black hairy tongue might change the normal flora of the mouth. The discoloration usually appeared after a few days treatment like this case [1-3].

Amir et al [6] have reported a 65-year-old kidney transplant recipient with tongue discoloration after receiving a 14 day course of linezolid. The discoloration resolved 6 months after the discontinuation of linezolid. Ma JS [7] has also reported a case of 8-year-old girl with the diagnose of bacteremia and polyarthritis presented with discoloration of the both incisors and tongue, 1 and 2 weeks after initiating linezolid therapy.

Black hairy tongue is a benign, reversible and very rare side effect due to linezolid. It can be omitted by the physicians, for this reason, this case was presented in here. 


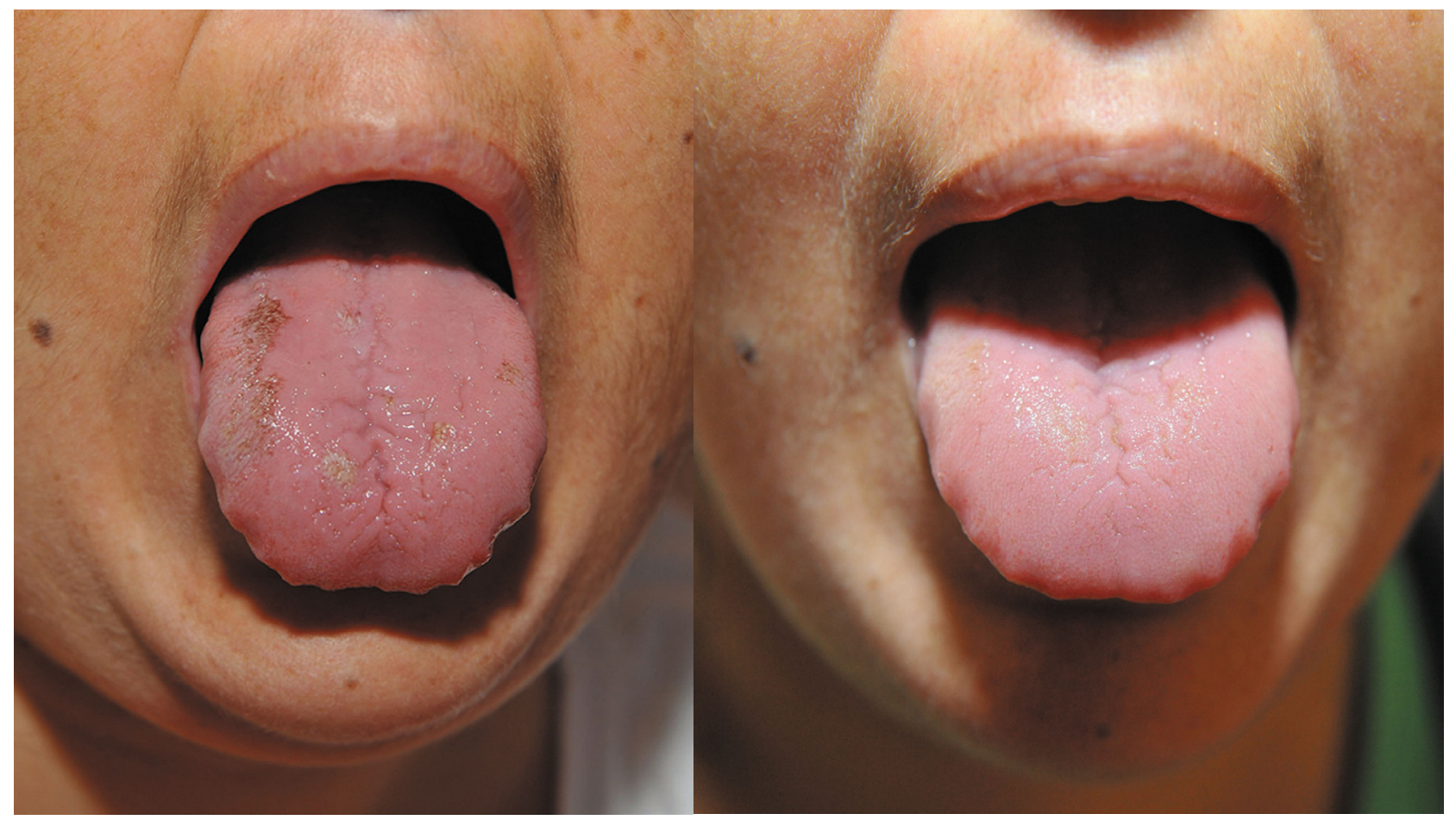

Figure 1.a. The appearance of black hairy tongue on the patients' tongue after 10 days receiving linezolid. b. Disappearance of the lesions

\section{REFERENCES}

1. Ioffreda MD, Gordon CA, Adams DR, Naides SJ, Miller JJ: Black tongue. Arch Dermatol 2001; 137: 967.

2. Greco S, Mazzaglia G, Caputi AP, Pagliaro L: Glossitis, stomatitis, and black tongue with lansoprazole plus clarithromycin and other antibiotics [letter]. Ann Pharmacother 1997; 31: 1548.

3. Jover-Diaz F, Cuadrado-Pastor JM, Talents-Bolos A, MartinGonzalez C: Black tongue associated with linezolid. Am J Ther 2010; 17: 115-117.
4. Gould FK: Linezolid: safety and efficacy in special populations. J Antimicrob Chemother 2011;66 (14):3-6.

5. Hau T: Efficacy and safety of linezolid in the treatment of skin and soft tissue infections. Eur J Clin Microbiol Infect Dis 2002; 21: 491-498.

6. Amir KA, Bobba RK, Clarke B, Nagy-Agren S, Arsura EL, Balogun SA, et al: Tongue discoloration in an elderly kidney transplant recipient: treatmentr elated adverse event. Am J Geriatr Pharmacother 2006; 4: 260-263.

7. Ma JS: Teeth and tongue discoloration during linezolid therapy. The Pediatr Infect Dis J 2009; 28: 345-346.

Copyright by Ilkay Bozkurt, et al. This is an open access article distributed under the terms of the Creative Commons Attribution License, which permits unrestricted use, distribution, and reproduction in any medium, provided the original author and source are credited. 